\title{
(RE)PLANEJANDO AULAS DE CIÊNCIAS: O CONTEXTO DE UM CENTRO DE ATENDIMENTO SOCIOEDUCATIVO DE GOIÂNIA
}

\author{
Aline Neves Vieira Santana \\ MARILDA SCHUVARTZ \\ José Firmino de Olivelra Neto \\ Universidade Federal de Goiás (UFG), Goiânia, Goiás, Brasil
}

\begin{abstract}
Resumo: O objetivo deste trabalho centraliza-se em apresentar a elaboração do planejamento de aulas de Ciências em uma escola que atende os jovens em conflito com a lei enquanto cumprem a medida socioeducativa de internação em Goiânia. Portanto, percebe-se a necessidade de uma abordagem qualitativa nos moldes da pesquisa participante. Para a construção dos dados opta-se pela elaboração do planejamento de aulas com a professora de ciências da Unidade Escolar. Constatou-se que tratando deste perfil de estudante, da imersão da escola dentro de um ambiente de restrição e privação momentânea de liberdade, da ausência de legislação e de um currículo específico, são atitudes simples no fazer escolar que podem permitir a esses jovens a possibilidade de adoção de procedimentos e atitudes frente à sociedade através dos conteúdos.
\end{abstract}

Palavras-chave: Adolescentes em conflito com a lei. Ensino de ciências. Planejamento de aula.

"A prática educativa é tudo isso: afetividade, alegria, capacidade científica, domínio técnico a serviço da mudança ou, lamentavelmente, da permanência do hoje" (FREIRE, 2011, p. 140). 
INTRODUÇÃO

Historicamente a ação de planejar faz parte do cotidiano da humanidade (BAFFI, 2002). Ao pensar suas atividades diárias o homem realiza essa ação, assim, de uma forma ou de outra, de uma maneira empírica ou científica, planeja (MENEGOLLA; SANT'ANNA, 2003). Nesse movimento, compreende-se que o planejamento é o "ato ou efeito de planejar" (FERREIRA, 2011 , p. 1575). Porém, pensando no processo de ensino-aprendizagem, foco deste trabalho, a definição é reducionista, reportando a necessidade de clareza e aprofundamento acerca do conceito.

Antes de adentrar ao conceito faz-se elucidar, como reporta Cunha (1998, p. 17), que "a concepção de conhecimento preside a definição da prática pedagógica", os processos de ensino-aprendizagem estão alicerçados em uma concepção de mundo, de ciência. São estas bases epistemológicas que fundamentaram o fazer docente, de forma consciente ou não, durante a ação de construção dos planos.

Libâneo (1994, p. 221) afirma que o planejamento "é um meio para se programar as ações docentes, mas é também um momento de pesquisa e reflexão intimamente ligado à avaliação"; corroborando com Libâneo (1994), Haydt (2006, p. 94) argúi que "é um processo mental que envolve análise, reflexão e previsão". Nesse sentido, tem como características: "evitar a improvisação, prever o futuro, estabelecer caminhos que possam nortear mais apropriadamente a execução da ação educativa, prever o acompanhamento e a avaliação da própria ação" (BAFFI, 2002, p. 2).

Dessa forma, a construção do planejamento da aula representa um momento de autonomia, de reflexão, de decisão, de comprometimento e de criatividade por parte do professor que intenta possibilitar um trabalho mais significativo, colaborativo e comprometido com a efetivação dos objetivos escolares (LIBÂNEO, 1994; MEIRIEU, 2005; VEIGA, 2008). Infere-se nesse momento, juntamente com Freire (2011, p. 11), que "a prática educativa é tudo isso: afetividade, alegria, capacidade científica, domínio técnico a serviço da mudança ou, lamentavelmente, da permanência do hoje", coloca-se em evidência nuances que se dão subjetivadas no processo de planejamento, mas que devem se constituir como premissas do mesmo intentando um ensinoaprendizagem divergente, em outras palavras, que se contraponha a lógica estabelecida (Neoliberal) e efetive a emancipação dos sujeitos.

Contribuindo com a discussão, essa ação pressupõe a existência de alguns elementos essenciais na sua construção. Portanto, a constituição do planejamento, segundo Libâneo (1994), prevê a inclusão do conjunto de componentes como: os objetivos, as finalidades, os conteúdos, as estratégias 
didáticas e os sujeitos do processo, tendo em vista os meios e as condições previamente decididas.

Elucida-se ainda, nesse panorama sobre o planejamento, a dialética entre planejar e replanejar (Figura 1). A ação docente é mediada por inúmeras variáveis, a citar a indisciplina e as dificuldades de aprendizagem do alunado. Portanto, não se constitui como linear o que reporta a um exercício constate de tomada de decisão por parte dos professores durante o processo de mediação do conhecimento, constituindo a ação de replanejar. Buscam-se neste processo caminhos outros para se alcançar os objetivos propostos para a aula.

Figura 1 - Relação dialética entre planejamento e replanejamento

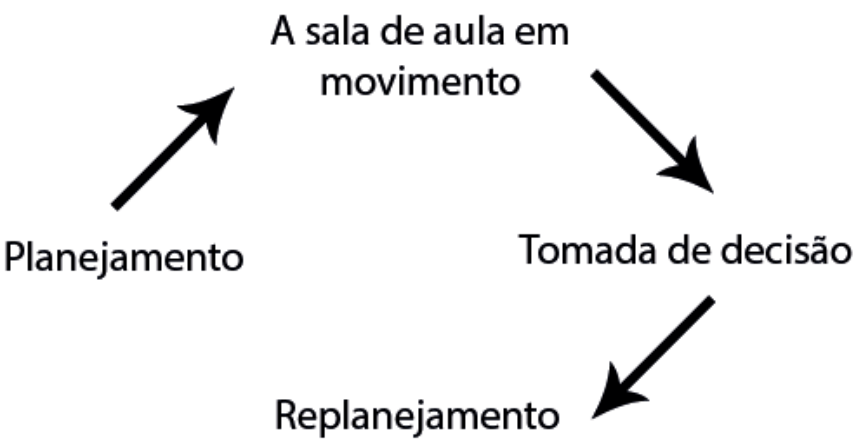

Fonte: SANTANA, A. N. V.; SHUVARTZ, M.; OLIVEIRA NETO, J. F.

Assim, entende-se neste trabalho que o ato educativo é complexo, corroborando que planejar pressupõe replanejar, ou seja, intentar-se para as incertezas que surgem durante a prática educativa e a necessidade de se tomar decisões frente a essas, ressignificando o processo de ensino-aprendizagem.

Diante do exposto, a presente investigação apresenta como objetivo compreender como as aulas de Ciências são planejadas em um Centro de Atendimento Socioeducativo de Goiânia-GO, no qual se encontram adolescentes em conflito com a lei, privados e restritos de liberdade enquanto cumprem a medida socioeducativa de internação. Nesta instituição, ressaltamse três elementos singulares que distam daqueles presentes em qualquer outra escola, a saber: a ausência de uma legislação educacional especial e de um currículo específico, a imersão em uma Unidade de Atendimento Socioeducativa e o perfil dos estudantes. Porém, intenta-se destacar que as posturas assumidas na construção dos planos das aulas permitem a efetivação das propostas contempladas nos documentos oficiais da área, assim como nos referenciais teóricos em Ensino de Ciências. 
O SISTEMA SOCIOEDUCATIVO: O PROCESSO DE ENSINO-APRENDIZAGEM E SUAS ESPECIFICIDADES

Embora se reconheça a complexidade da questão que leva o adolescente a cometer um ato infracional, a citar as questões de ordem política, social e econômica, não se exime a culpa desse jovem, o que significa não deixá-lo isento de consequências. Por conseguinte, entende-se a importância da legislação especial vigente que prevê medidas socioeducativas baseadas nas noções de pessoa em condição peculiar de desenvolvimento (BRASIL, 1990).

Portanto, o princípio fundamental do Estatuto da Criança e do Adolescente (ECA) está assentado na ideia de proteção integral a todas as crianças e adolescentes, e impõe com prioridade e universalidade uma política para esses sujeitos ao assegurar direitos como a saúde, a educação, a convivência familiar, entre outros. Deste modo, certifica o valor prospectivo da infância e adolescência como portadora de continuidade da nação e a sua situação de vulnerabilidade.

Mas, para sistematizar as normas, fortalecer e fazer cumprir essa política de atendimento dos direitos desse grupo de jovens autores de ato infracional expressas no ECA, inicia-se a partir das avaliações nacionais realizadas pelas próprias direções das entidades e/ou programas de atendimento socioeducativo de internação pesquisadas em 2002 pelo Ministério da Justiça, a elaboração de um documento que propõe diretrizes claras e específicas para o reordenamento institucional da execução das medidas socioeducativas, a fim de certificar o compromisso com os direitos humanos (ROCHA, 2002; LOBO, 2011; BORGES, 2012).

Da escrita desse documento em 2006, fundou-se o Sistema Nacional de Atendimento Socioeducativo (SINASE), que regulamenta a execução das medidas destinadas ao adolescente que pratique ato infracional, que posteriormente foi instituído pela Lei no 12.594, sancionada em de 18 de janeiro de 2012.

Mas, desde a promulgação da Constituição Federal de 1988 sabese que "a educação é direito de todos e dever do Estado e da família, será promovida e incentivada com a colaboração da sociedade, visando ao pleno desenvolvimento da pessoa, seu preparo para o exercício da cidadania e sua qualificação para o trabalho"(BRASIL, 1988, p. 34). Logo, afirma o reconhecimento da escolaridade como requisito iniludível para o desenvolvimento do cidadão. Para tanto, independente da conduta ilícita tipificada como ato infracional, entende-se que a este grupo de adolescentes deve ser destinado uma medida socioeducativa com horizonte de formação, educação e cidadania. Desse modo, a finalidade da escola ultrapassa a construção de conteúdo conceitual a fim de refletir a prática do respeito aos direitos humanos. 
Para os adolescentes que cometem um ato infracional grave é aplicada a medida socioeducativa de internação, que deve ser cumprida por até três anos em estabelecimento educacional. Assim, entende-se que há um lócus, que conta com uma estrutura física e profissional a fim de receber e garantir os direitos dos jovens. Desse modo, este espaço "arquitetônico unifica, concentra, integra o atendimento ao adolescente com autonomia técnica e administrativa, com quadro próprio de pessoal, para o desenvolvimento de um programa de atendimento e um projeto pedagógico específico" (BRASIL, 2006, p. 59).

Porém, a ausência de uma legislação educacional especial e de um currículo específico faz com que a autonomia da escola imersa em um Centro de Atendimento Socioeducativo seja subordinada às normas, às rotinas de segurança e aos outros atendimentos técnicos e, assim, neutralize o campo pedagógico como elemento potencializador de mudanças na formação e vivência desses jovens, como coloca Julião (2010).

O processo de ensino-aprendizagem nesse contexto se dá, portanto, repleto de especificidades, as quais necessitam serem entendidas e discutidas. Assim, aludisse sobre a necessidade de compreensão das práticas educativas realizadas nesses espaços com vista ao trabalho que seja contextualizado, crítico e, sobretudo, dialógico. É nesse viés que a pesquisa se constituiu.

\section{A PESQUISA}

A investigação trata-se de uma pesquisa de caráter qualitativo, nos moldes da abordagem de pesquisa participante. Para Lüdke e André (1986), compreende-se a pesquisa qualitativa por interpretar a fala, a escrita, os gestos e as ações de professores e de alunos. Acerca da pesquisa participante, Demo (2008) aponta que nesta há um componente político que possibilita discutir a importância do processo de investigação tendo por perspectiva a intervenção na vivência social.

A partir dessas premissas da pesquisa apresentar-se-á neste trabalho os momentos de diálogo para construção de um planejamento com a professora de Ciências da Escola Estadual Vida Nova sediada no CASE de Goiânia - GO, a qual possui como alunos, adolescentes em conflito com a lei imersos em um contexto de privação e restrição momentânea de liberdade.

Entende-se a necessidade de agendar e trocar experiências e ideias com a professora de Ciências a partir de autores como Libâneo (1994) e Zabala (1998), que defendem o planejamento da aula como uma ação não mecânica.

Essa conversa culminou numa discussão baseada nos referenciais elencados acima e assim surgiram dez planos de aula. Durante a elaboração dos planos, ao explicitar os objetivos, o espaço físico, a dimensão temporal, 
os recursos didáticos, o desenvolvimento de conteúdos, as estratégias de ensino e os sujeitos do processo de ensino e aprendizagem, os dados foram coletados e registrados em diário de campo.

A instituição escolar encontra-se submissa ao atendimento da unidade socioeducativa e, portanto, as atividades educacionais, quando ocorrem, são descontínuas e atropeladas pelas dinâmicas e lógicas da segurança local. A professora da disciplina de Ciências é graduada em História e com 3 anos de exercício no magistério.

Sobre o espaço físico da investigação faz-se salientar ainda que o mesmo corresponde a três salas de aula com capacidade máxima de 15 alunos. De acordo com o Projeto Político Pedagógico (PPP) da instituição, as instalações encontram-se em péssimo estado de conservação no que se refere à estrutura geral do prédio, não possuem banheiro próprio para alunos e funcionários, tampouco espaço para funcionar a cozinha, a recreação, a biblioteca, a sala dos professores e a quadra de esportes.

A fim de superar a dicotomia existente entre pesquisadora e professora e, intentando estimular novos olhares para os profissionais que atuam, para planejar as aulas, ficou acordado que a professora de Ciências da escola deixasse a posição de colaboradora da investigação e passasse a participar do planejamento e do desenvolvimento das aulas em conjunto com a pesquisadora. Assim, com mais elementos de apropriação da vivência local, as aulas foram elaboradas conforme o relato a seguir.

A troca de ideias sobre como seriam as aulas ocorreu nos meses de agosto e setembro de 2012 , no intervalo de $7 \mathrm{~h}$ às $8 \mathrm{~h}$ e de $13 \mathrm{~h}$ às $14 \mathrm{~h}$, período do dia em que as professoras ficavam disponíveis na escola, realizando o planejamento e aguardando o horário de desenvolvimento das aulas. Nesse tempo definiram-se os objetivos da disciplina, o conteúdo, as estratégias didáticas e os recursos, considerando o tempo e o espaço disponíveis, bem como os sujeitos do processo, o professor e os alunos.

Os diálogos culminaram na origem de (10) dez planos de aula. Mas apesar de serem elaborados dez planos de aula, somente (03) três foram privilegiados para o desenvolvimento.

\section{(Re)Pensando as aulas de CiênCias: diálogos acerca da Construção do CONHECIMENTO No Atendimento SOCIOEducativo}

A docente que ministra as aulas de Ciências é do sexo feminino, 47 anos, graduada em História e efetiva da rede de educação do Estado de Goiás. Quanto ao exercício da docência, está neste há 11 anos. Esses dados vão de encontro com a legislação e com as discussões da profissionalidade docente, 
que enfatizam a obrigatoriedade do curso superior, bem como o estímulo para a realização de concursos públicos (BRASIL, 1996). Porém, reitera-se um retrato da educação nacional, professores que ministram disciplinas que não estão ligadas a sua área de formação inicial, no caso uma professora de História ministrando aulas de Ciências.

Com relação à carga horária de trabalho, a docente, para além do CASE, completa suas horas semanais em uma escola regular. Argúi que possui um regime de 40 horas, sendo 28 horas em sala de aula. Nesse sentido, pondera-se que este é um fator que dificulta a organização do trabalho pedagógico pela professora, haja vista que a ação de planejar envolve análise, reflexão e previsão, como coloca Haydt (2006).

Para tanto, após o entendimento de como estrutura-se a rotina do CASE e consequentemente da escola, iniciou-se o diálogo para a escrita dos planos de aula. Para Libâneo (1994), o primeiro elemento deste refere-se aos objetivos gerais, estabelecidos em consonância com o PPP da Unidade Educacional, com as políticas educacionais e com os referenciais teóricos privilegiados (COLL et al., 2000; FREIRE, 2005), que defendem que os objetivos da educação devem ir além da compreensão dos conhecimentos e informações, envolvendo procedimentos e atitudes.

No contexto socioeducativo há, ou ao menos se espera que haja, um olhar atento para os dois últimos elementos pontuados acima, os procedimentos e as atitudes. Para além da apropriação de conceitos, esperase que esse aluno por meio deste ensino se integre de uma forma distinta a que o fez chegar no CASE. Assim, mediar o conhecimento é integrar reflexão, crítica e ética para elucidar princípios outros ${ }^{4}$ e tentar uma mudança de comportamento do alunado após o tempo de privação e restrição de liberdade.

Para tanto, dando continuidade ao planejamento das aulas com a professora de Ciências, outra variável abordada relaciona-se com o desenvolvimento de conteúdos referentes a conceitos, procedimentos e atitudes para o Ensino Fundamental II. Assim, como a sequência didática da docente abordava os conteúdos de Água e Solo, privilegiou-se trabalhar a partir da horta existente na instituição.

Em convergência com a fundamentação teórica adotada e com o objetivo geral a que serve a pesquisa, determinou-se que o papel da abordagem conceitual seria reconsiderado para estabelecer uma relação complementar, de dependência mútua entre os diversos tipos de conteúdo, que podem influenciar os adolescentes em conflito com a lei desta unidade escolar a conceber novas referências de procedimentos e de atitudes. 
Para tanto, em um roteiro de tarefas e temas originou-se dez planos de aula (PA), a saber: Recepção dos estudantes; Produzindo a composteira; Construindo um minhocário; Cultivando Flores; Acompanhando a formação das cadeias alimentares; Aprendendo sobre uma dieta balanceada; Experimentando a cozinha, celebrando a vida; A Horta de Poteiro ; (Re) conhecendo a água; e Entrelace de Elementos: a água, as minhocas e a horta.

Avançando na construção dos planos de aula, sobreveio a seleção das estratégias de ensino, entendidas como o detalhamento do desenvolvimento da aula que revelam a concepção de ensino adotada e as intencionalidades docentes. Desse modo, representam o conjunto de disponibilidades pessoais, instrumentais e ações que o professor cumprirá durante o processo de ensino-aprendizagem.

Assumindo uma postura de entendimento da prática educativa como uma prática social, as estratégias escolhidas intentam propiciar aos alunos aprendizagens voltadas ao exercício da autonomia. Segundo Ferreira (2011, p. 120), autonomia significa"a faculdade de se governar por si mesmo; o direito ou faculdade de se reger por leis próprias; liberdade ou independência moral ou intelectual". Isso implica que o aluno seja o sujeito de sua aprendizagem, e que dele é o movimento de ressignificação da sua própria autonomia para aprender.

Sabe-se que a formação de um sujeito autônomo envolve a assunção deste como ser social e histórico que se constitui a partir de inúmeras decisões. Logo, as estratégias de ensino selecionadas são artifícios que dão condições para que este processo aconteça, desenvolvendo o pensamento crítico do aluno à medida que se agrega a ele uma dimensão dialógica (FREIRE, 2005).

A fim de contemplar as diferenças individuais e motivar os alunos, foram privilegiadas atividades diversas para uma intervenção dialógica e problematizadora, dentre as quais: a experimentação investigativa e a discussão estruturada. Essas metodologias propostas convergem ao superar o individualismo e direcionar para uma prática cooperativa com os pares e com o objeto do conhecimento por meio do qual se constrói a aprendizagem (MARANDINO; SELLES; FERREIRA, 2009). E ainda, romper com um ciclo tradicional que domina a educação, no qual a aula expositiva é a estratégia mais empregada, como afirma Krasilchik (1983).

Faz-se salutar que as metodologias escolhidas não são sugeridas no PPP da escola. O PPP sugere metodologias, como: gincanas, debates, júris simulados, teatro, produção de texto, cine fórum, pesquisas bibliográficas, simulados e palestras. Em suma, pressupõe o uso de metodologias ativas. Porém, em conversa com a docente e a permanência no local, pouco se vê o emprego de metodologias como as citadas acima. Assim, as aulas não se 
distanciam de um modelo de ensino tradicional. Logo, por meio da questão, a metodologia para as aulas foi proposta.

Sobre a utilização de recursos didáticos, verifica-se conjuntamente com a professora que a seleção destes precisa ser de muita cautela, considerando a restrição na variedadede materiais. O fato de desenvolver um trabalho em uma escola que atende alunos em uma Unidade de privação e restrição momentânea de liberdade, a reserva de materiais decorre como forma de garantir a segurança do local. Assim, não é permitido o uso de tesoura com ponta e estilete, por exemplo, bem como os alunos não possuem cadernos com espiral, fazendo as atividades em folhas de papel sulfite que recebem no início de cada aula. Todas essas questões afetam a ação de planejar no interior do CASE.

O papel dos recursos físicos e materiais é o de incentivar e apoiar o processo de ensino-aprendizagem. Dessa forma, quando se trabalha na perspectiva de um conhecimento que se constrói para garantir a autonomia pessoal dos alunos em interação com os pares numa estrutura permanente de diálogo e problematização, a inclusão de recursos na aula deve colaborar com a dinâmica de tarefas integradas ao currículo.

Quando na área de ensino de Ciências reconhece-se a importância das mídias, bem como das tecnologias da informação e comunicação envolvidas com a inclusão digital dos alunos, verifica-se que pouco desta discussão encontra-se no CASE, embora existam recursos audiovisuais e de informática na Unidade carecendo de manutenção, de planejamento por parte dos docentes e de autorização da equipe que monitora a segurança local.

A fim de zelar pela segurança, foram utilizados materiais construídos pelos alunos através de práticas de respeito à autonomia, à criatividade, à colaboração, adequadas à idade, ao nível de escolaridade e relacionados à vivência dos estudantes. No planejamento elencou-se apenas materiais que não traziam riscos, entre os quais cita-se: folha de papel pardo, barbante, tesoura sem ponta, lápis de cor, garrafa pet, cola branca, pincel atômico e material biológico.

Prosseguindo com o planejamento das aulas, outra especificidade de trabalho no local foi explicitada, a dimensão temporal da aula. Enquanto que em outras escolas organiza-se em horas-aula de 45 ou 50 minutos, esse elemento não se apresenta consolidado neste espaço. Contudo, essa organização de tempo rígida, em horas-aulas que expressam o tempo cronológico em que se dividem as aulas em períodos do dia, intervém na disposição do processo didático em que se desenvolvem as ações, os meios e as condições para a efetivação do processo de ensino-aprendizagem. 
Portanto, a flexibilidade do tempo, utilizado como instrumento de controle em outros espaços educativos, dista da escola do CASE, e deve ser aproveitado pelo professor como variável favorável para a formação do aluno ao permitir meios que favoreçam o trabalho em oficinas e a realização de discussões estruturadas. Por isso, acordou-se que as aulas de ciências posteriormente desenvolvidas no CASE encerrar-se-iam quando esgotassem os apontamentos dos alunos.

Dando sequência às discussões com a professora, seguiu-se para o espaço físico destinado ao desenvolvimento das aulas. Por questões de segurança, a mobilidade dos alunos fora da Unidade é inviável, mas em experiências anteriores no exercício da docência neste local, percebeu-se uma oportunidade de construir conhecimento por meio da utilização da horta existente no CASE. A horta como ferramenta de ensino pode estimular o diálogo e a expressão por meio da fala e das ações, além disto, segundo Sato (2004), os alunos podem apropriar-se de elementos como a observação, o contato e a imersão na natureza. Estes elementos despertam a curiosidade que, por vezes, foge aos conteúdos pré-definidos no planejamento das aulas e facilitam a aprendizagem.

Assim, Viveiro (2006) aponta que os ambientes mais próximos à escola normalmente são mais acessíveis. Portanto, a partir da amplitude de possibilidades geradas pelo reconhecimento do ambiente, percebe-se que podem ser abordados problemas relacionados com outras áreas do conhecimento explorando a horta de maneira interdisciplinar (MERGULHÃO; VASAKI, 2002). Nessa perspectiva, a interdisciplinaridade"se traduz como um trabalho coletivo que envolve conteúdos, disciplinas e a própria organização da escola" (LOUREIRO, 2004, p. 76).

Logo, a atividade pedagógica proposta para ser realizada na horta não se resume à produção de alimentos, mas num laboratório de ação participativa, onde há formação de procedimentos e de atitudes sensíveis à complexidade do mundo.

Corroborando com a ideia de vincular a aula a outros espaços que não as quatro paredes da sala de aula, optou-se também pelo trabalho com a horta, tendo em vista esta como um espaço não formal de ensino (TRILLA; GHAEM, 2008). Pode-se compreender que as atividades desenvolvidas nesses espaços propiciam as relações entre os sujeitos envolvidos no processo educativo, requerendo outra postura, diferente da consolidada na rotina da sala de aula.

$\mathrm{O}$ aluno enquanto sujeito ativo do seu processo de aprendizagem trará questionamentos, o que instigará o debate e a discussão coletiva. A partir deste diálogo, surge uma oportunidade para o docente reestruturar sua prática pedagógica, com metodologias de ensino ativas que permitem 
novas formas de construção dos conteúdos em um ambiente que não tem essa perspectiva, como é a escola do CASE.

Dando sequência à preparação dos planos de aula, segue-se para a discussão a respeito da turma selecionada para a pesquisa, uma vez que essa profissional ministra aulas nos dois turnos da escola. Assim, esteve posto que a investigação fosse desenvolvida no período vespertino, pois somente nesse tempo a docente trabalha com a disciplina de Ciências e com adolescentes que estudam no Ensino Fundamental II.

A classe composta por 12 alunos do sexo masculino, considerados de alto risco de infração, com faixa etária entre 15 e 18 anos, de estudantes da $2^{\text {a }}$ etapa da Educação de Jovens e Adultos (EJA). Desta amostra de adolescentes averigua-se que o nível escolar em relação à idade cronológica é baixo, sendo que somente três destes estavam matriculados quando cometeram o ato infracional.

Esse perfil de escolarização refere-se a situações complexas, dentre as quais cita-se a exclusão escolar, o comportamento imediatista desses adolescentes, as dificuldades em cumprir normas, as precárias condições financeiras e a desestruturação da família. A questão é recorrente e para tal aparece em distintas pesquisas, a citar: Brancalhão (2003); Gallo (2006) e Zamora (2008).

Partindo do conjunto de elementos postos para mobilizar as comunicações na aula (os objetivos, os conteúdos, as estratégias de ensino, os recursos e o tempo), bem como o perfil dos alunos. Entende-se, com base em referenciais teóricos, como Libâneo (1994) e Freire (2005), que para as atividades e as sequências didáticas terem um efeito educativo, não se pode dicotomizar a tarefa de aprender do aluno, do ofício de ensinar do professor.

Essas relações interativas em sala de aula correspondem a "dois processos que se comunicam, mas não se confundem" (WEISZ, SANCHEZ, 2012, p. 65), promovendo uma relação de socialização, na qual os professores trocam experiências tornando-se parceiros e atores de sua própria formação.

Além de uma postura profissional que sistematiza as intenções educativas, que conduz as aulas por momentos de problematização e discussão entre os pares, que observa e intervém, Cella (2007) apresenta outros componentes indispensáveis à prática docente para a vivência com esses jovens que se encontram em conflito com a lei. Entre eles, a disposição para ouvir e a valorização desse adolescente sem discriminação ou hipocrisia.

O diálogo com a professora se encerrou com as discussões sobre a avaliação da aprendizagem, a qual pode ser compreendida como um processo de aperfeiçoamento que permeia a prática pedagógica, e intenta diagnosticar e direcionar outras possibilidades para a condução do processo de ensinoaprendizagem. Os instrumentos de coleta de dados para a avaliação devem 
ser minuciosamente pensados e estarem atrelados com o restante do plano construído, principalmente aos objetivos propostos.

Para tanto, pretendendo tornar efetivas as aulas elaboradas, as propostas assinaladas pelos referenciais outrora supracitados e nas políticas públicas, tomou-se por referência o $5^{\circ}$ parágrafo do artigo 24 da LBD (Lei 9.394/96), que expressa o caráter formativo das avaliações "com prevalência dos aspectos qualitativos sobre os quantitativos e dos resultados ao longo do período sobre os de eventuais provas finais (BRASIL, 1996, p. 08). Dessa forma, pode-se notar a estreita relação com os outros elementos constituintes da aula anteriormente assinalados. E, para firmar o compromisso com a formação integral desses adolescentes em privação de liberdade, o tipo de avaliação e os meios propostos para o redimensionamento da aprendizagem foram para alcançar o maior grau de competências por parte do aluno, com vistas à garantia da qualidade do ensino.

Mediante o exposto, coloca-se que todo o diálogo realizado intentouse para a análise, reflexão e previsão, características pontuadas por Haydt (2006) quando da definição de planejamento. Portanto, planejar é processo, ação e, sobretudo, previsão. Nesse momento pontua-se ainda que todas as ações delineadas no plano, como já se respaldou neste trabalho, podem e devem, se necessário, serem replanejadas, pois o mais importante é propiciar uma aprendizagem significativa e não apenas cumprir o prescrito.

Pondera-se ainda que durante a elaboração dos planos a professora demonstrava dificuldades para planejar as aulas, sobretudo quando se colocava em questão um movimento de problematização e conhecimento do contexto do alunado. Imbricada a um modelo de aula tradicional, a professora relegava a criatividade, imaginação e o diálogo com o alunado, separando as atividades de raciocínio daquelas imaginativas, como se tratasse de áreas distintas do pensamento.

Acredita-se que as dificuldades reportadas pela professora sejam fruto de um modelo de formação também arraigado nestes princípios (tradicionais), e ainda pelo fato de ministrar uma disciplina distinta de sua área de formação, o que demanda outra forma de organização da aula. Faz-se ainda necessário salientar aqui que o conhecimento do conteúdo específico é imprescindível, e que por vezes determina a metodologia a ser empregada. E, por fim, identifica-se uma distância entre o que está proposto nos documentos oficiais voltados para o Ensino de Ciências, a citar o uso de metodologias ativas e uma abordagem histórica dos conteúdos com as práticas da professora. 


\section{CONSIDERAÇÕES FINAIS}

Por estar a escola inserida em um ambiente socioeducativo, cabe proceder com algumas medidas de segurança partindo do pressuposto que se trata de jovens autores de ato infracional. Portanto, faz-se necessário a existência de um PPP e um currículo que esteja de acordo com as especificidades do Sistema Socioeducativo.

No entanto, tudo o que foi vivenciado na construção das aulas corrobora para a constatação da falta de uma política educacional específica para o Sistema Socioeducativo. Sem orientações nacionais específicas não há possibilidade de acompanhamento ou de avaliação das atividades empreendidas pela falta de parâmetros ou diretrizes. Uma vez que na Unidade do CASE a educação é relegada a um segundo plano, a natureza sancionatória da medida socioeducativa de internação prevalece sobre o caráter pedagógico.

Todavia, durante o planejamento das aulas de Ciências com a professora desta disciplina, os referenciais teóricos da área privilegiados e os documentos oficiais sinalizaram componentes necessários à efetivação das potencialidades desta área como prática problematizadora. Assim, atentouse para o planejamento de uma prática transgressora na via de contestação do sistema e colocando o pedagógico em evidência, em que se buscou considerar as especificidades locais e as inter-relações que os elementos componentes da aula podem alcançar.

As intencionalidades educativas expressas no planejamento das aulas bem como no seu desenvolvimento possibilitam os caminhos para condução do aprendizado, logo, resgatou-se no planejamento pedagógico das aulas o compromisso com as novas maneiras de apreender e fazer Ciências, ampliando as vivências cidadãs pouco empregadas até então.

Por fim, coloca-se que este trabalho tenta colocar em evidência um contexto pouco conhecido pela sociedade e, portanto, negado na formação de professores e nas políticas públicas em sua maioria. Reporta-se com via nessa elucidação a necessidade do desenvolvimento de políticas educacionais para o contexto do Sistema Socioeducativo, e ainda a necessidade de desenvolvimento de pesquisas no mesmo, intentando para uma ação docente consciente e crítica, com vista à transformação dos sujeitos que aprendem (professores e alunos). 
(RE) PLANNING CLASSES OF SCIENCES: THE CONTEXT OF A CENTER FOR SOCIAL EDUCATION IN GOIÂNIA

ABSTRACT: The aim of this paper is mainly focused on the elaboration of a new Sciences schedule in a school where teenagers have already broken (justice conflicts) and study in rehab institutions. To realize this work and the construction of data we've opted for the elaboration of classes planning with the Scholar Unit Teacher. It was verified that treating this specific student profile, the imersion of the school inside of a restriction atmosphere and momentary privation of freedom, the legislation absence and without any specific curriculum, there are simple attitudes at school that can give these teenagers the possibility of adopting procedures and attitudes into the society through the contents.

KEYWORDS: Adolescents in conflict with the law. Science teaching. Lesson planning.

(RE)PLANEANDO CLASES DE CIENCIAS... EL CONTEXTO DE UN CENTRO DE ATENCIÓN SOCIOEDUCATIVA DE GOIÂNIA

RESUMEN: El objetivo de este trabajo se centra en presentar la elaboración del planeamiento de clases de Ciencias en una escuela que asiste a jóvenes en conflicto con la ley mientras cumplen la medida socioeducativa de internación en Goiânia. Por lo tanto, se nota la necesidad de un abordaje cualitativo en los moldes de la investigación participante. Para la construcción de los datos se opta por la elaboración del planeamiento de las clases con la profesora de Ciencias de la Unidad Escolar. Se constató que, tratándose de este perfil de estudiante, de la inmersión de la escuela dentro de un ambiente de restricción y privación momentánea de libertad, de ausencia de legislación y de un currículo específico, son las actitudes simples en el desarrollo diario de la escuela las que pueden permitir a estos jóvenes la posibilidad de adopción de procedimientos y actitudes frente a la sociedad a través de los contenidos.

Palabras Clave: Adolescentes en conflicto con la ley. Enseñanza de ciencias. Planeamiento escolar.

\section{NOTAS}

1) O plano é o documento que consolida a ação de planejar.

2) A modulação dos professores é realizada na lotação destes para uma única escola. Como a unidade escolar é dividida em três polos distantes, para não haver locomoção dos profissionais que ali atuam, cada docente para completar a carga horária ministra mais de uma disciplina, independente de sua área de formação. Esse fator burocrático, 
que não compreende as especificidades do local, contribui com a multisseriação dos alunos.

3) Apesar da SEDUCE destinar tempo para o planejamento das aulas na carga horária do professor, este não tem convergido para um momento de disponibilidade coletiva. Este foi o argumento pelo qual os demais professores que ministram aulas de disciplinas específicas no CASE não puderam participar dessa etapa da investigação.

4) Aqui se quer atentar para um conhecimento para além da memorização de conceitos.

5) Nome fictício empregado para o plano de aula. Antonio Poteiro é um artista plástico goiano; na aula buscou-se uma relação entre suas obras e o contexto da horta escolar.

\section{REFERÊNCIAS}

BAFFI, M. A. T. O planejamento em educação: revisando conceitos para mudar concepções e práticas. In: BELLO, J. L. P. Pedagogia em Foco, Petropólis, 2002. Disponível em: <http://www.pedagogiaemfoco.pro.br/fundam02.htm>. Acesso em: 19 jun. 2016.

BORGES, M. A. B. As implicações socioeconômicas, históricas e jurídicas na vulnerabilização das famílias dos adolescentes autores de ato infracional. 2012. 221f. Dissertação (Mestrado em Serviço Social) - Pontifícia Universidade Católica de Goiás, Goiânia, 2012.

BRANCALHÃO, W. R. D. A educação para o adolescente em conflito com a lei: mecanismo de inserção ou de exclusão social? 2003. 130f. Dissertação (Mestrado em Educação) - Universidade Estadual Paulista, Marília, São Paulo, 2003.

BRASIL. Constituição (1988). Constituição da República Federativa do Brasil. Brasília: Senado Federal: Centro Gráfico, 1988. 292 p.

. Lei $\mathrm{n}^{\circ} 8.069$, de 13 de julho de 1990. Estatuto da criança e do adolescente. Disponível em: <http://www.planalto.gov.br/ccivil_03/leis/L8069.htm>. Acesso em: 19 jun. 2016.

Lei no 9394, de 20 de dezembro de 1996. Lei de Diretrizes e Bases da Educação Nacional. Disponível em: <http://www.planalto.gov.br/ccivil_03/leis/L9394.htm>. Acesso em: 19 jun. 2016.

Sistema Nacional de Atendimento Socioeducativo-SINASE/ Secretaria Especial dos Direitos Humanos. Brasília: CONANDA, 2006. Disponível em: <http://www. conselhodacrianca.al.gov.br/sala-de-imprensa/publicacoes/sinase.pdf $\geq$. Acesso em: 19 jun. 2016.

Conselho Nacional de Educação - Câmara de Educação Básica. Diretrizes Nacionais para a oferta de educação para jovens e adultos em situação de privação de liberdade nos estabelecimentos penais - Parecer CNE/CEB n 4/2010. Disponível em: <http:// portal.mec.gov.br/index.php?option=com_docman\&view=download\&alias=4445-pceb004-10\&ltemid=30192>. Acesso em: 19 jun. 2016. 
. Lei $n^{\circ} 12.594$, de 18 de janeiro de 2012. Sistema Nacional de Atendimento Socioeducativo. Disponível em: <http://www.planalto.gov.br/ccivil_03/_ato20112014/2012/lei/l12594.htm>. Acesso em: 19 jun 2016.

CELLA, S. M. A formação de professores para educação de adolescentes em conflito com a lei. 2007. 212f. Dissertação (Mestrado em Educação) - Pontifícia Universidade Católica de Campinas, Campinas, 2007.

COLL, C. et al. (Org.) Os conteúdos na reforma: ensino e aprendizagem de conceitos, procedimentos e atitudes. Porto Alegre: Artmed, 2000.

CUNHA, M. I. O professor universitário na transição de paradigmas. Araraquara, SP: JM Editora, 1998.

DEMO, P. Pesquisa Participante: saber pensar e intervir juntos. 2. ed. Brasília: Série Pesquisa Líber Livro, 2008.

FERREIRA, A. B. H. Dicionário Escolar da Língua Portuguesa. 2. ed. Curitiba: Editora Positivo, 2011.

FREIRE, P. Pedagogia do oprimido. 42. ed. Rio de Janeiro: Editora Paz e Terra, 2005.

. Pedagogia da Autonomia: saberes necessários à prática educativa. 5. ed. Rio de Janeiro: Editora Paz e Terra, 2011.

GALLO, A. E. Adolescentes em conflito com a lei: perfil e intervenção. 2010. 300 f. Tese (Doutorado em Educação Especial) - Universidade Federal de São Carlos, São Carlos, São Paulo, 2006.

HAYDT, R. C. C. Curso de Didática Geral. 8. ed. São Paulo: Ática, 2006.

JULIÃO, E. F. A ressocialização através do estudo e do trabalho no sistema penitenciário brasileiro. 2010. 433f. Tese (Doutorado em Ciências Sociais) - Universidade do Estado do Rio de Janeiro, Rio de Janeiro, 2010.

KRASILCHIK, M. Prática de ensino de Biologia. São Paulo: Harper \& Row do Brasil Ltda, 1983.

LIBÂNEO, J. C. Didática. São Paulo: Cortez, 1994.

LOBO, V. J. Considerações dos atores do sistema de garantia de direitos sobre o processo de execução da medida socioeducativa de privação de liberdade. 2011. 120 f. Dissertação (Mestrado em Psicologia) - Pontifícia Universidade Católica de Goiás, Goiânia, 2011.

LOUREIRO, C. F. B. Trajetória e fundamentos da educação ambiental. São Paulo: Cortez, 2004.

LÜDKE, M.; ANDRÉ, M. E. D. A. Pesquisa em Educação: Abordagens Qualitativas. São Paulo: EPU, 1986.

MARANDINO, M.; SELLES, S. E.; FERREIRA, M. S. Ensino de Biologia: histórias e práticas em diferentes espaços educativos. São Paulo: Cortez, 2009. 
MEIRIEU, P. O cotidiano da escola e da sala de aula: o fazer e o compreender. Porto Alegre: Artmed, 2005.

MENEGOLLA, M.; SANT'ANNA, I. M. Por que planejar? Como planejar? Currículo - Área - Aula. 13. ed. Petrópolis, RJ: Vozes, 2003.

MERGULHÃO, M. C.; VASAKI, B. N. G. Educando para a conservação da natureza: sugestões de atividades em educação ambiental. 2. ed. São Paulo: EDUC, 2002.

ROCHA, E. Mapeamento nacional da situação das Unidades de execução da medida socioeducativa de privação de liberdade ao adolescente em conflito com a lei. Brasília: IPEA/DCA-MJ, 2002. Disponível em: <http://www.sdh.gov.br/clientes/sedh/sedh/ spdca/prosinase/Pesquisas_MSE/spdca/prosinase/Pesquisas_MSE/mape/>. Acesso em: 20 jun. 2016.

SATO, M. Educação ambiental. São Carlos, SP: RiMa, 2004.

TRILLA, J.; GHAEM, E. Educação formal e não formal: pontos e contrapontos. São Paulo: Summus, 2008.VEIGA, I. P. A. (Org.). Aula: Gênese, dimensões, princípios e práticas. Campinas: Papirus, 2008.

VIVEIRO, A. A. Atividades de campo no ensino das ciências: investigando concepções e práticas de um grupo de professores. 2006. 172 f. Dissertação (Mestrado em Educação para a Ciência) - Universidade Estadual Paulista, Bauru, São Paulo, 2006.

WEISZ, T.; SANCHEZ, A. O diálogo entre o ensino e a aprendizagem. São Paulo: Ática, 2012. ZABALA, A. A prática educativa: como ensinar. Porto Alegre: Artmed, 1998.

ZAMORA, M. H. Adolescentes em conflito com a lei: um breve exame da produção recente em psicologia. POLÊM!CA Revista Eletrônica, Rio de Janeiro, 2008.

Aline Neves Vieira Santana: Doutoranda em Educação em Ciências e Matemática pela Universidade Federal de Goiás (UFG). Professora da Rede Estadual de Educação do Estado de Goiás.

E-mail: alinenevi@hotmail.com

Marilda Schuvartz: Doutora em Ciências Ambientais pela Universidade Federal de Goiás (UFG). Mestre em Educação Escolar Brasileira pela mesma Universidade. É professora no Instituto de Ciências Biológicas e no Programa de Pós-Graduação em Educação em Ciências e Matemática da UFG.

E-mail: marildas27@gmail.com 
SANTANA, A. N. V.; SCHUVARTZ, M.; NETO, J. F. de. O.

José Firmino de Oliveira Neto: Doutorando em Educação em Ciências e Matemática pela Universidade Federal de Goiás (UFG). Professor da Rede Municipal de Educação de Goiânia.

E-mail: neto.09@hotmail.com 